\title{
Effets environnementaux de la production de l'igname sur le système agroforestier dans la commune de Ouaké au Bénin
}

\author{
Moussa GIBIGAYE \\ Département de Géographie et Aménagement du Territoire/DGAT/Flash/UAC, Benin. \\ E-mail:moussa_gibigaye@yahoo.fr
}

\section{RESUME}

La présente étude vise à caractériser les pratiques culturales de l'igname dans la Commune de Ouaké et ses effets sur les ressources naturelles. Pour mener à bien ce travail, d'abord des entretiens ont eu lieu avec les conseillers du monde agricole et les producteurs de 16 villages de la Commune. Ensuite, les exploitations ont été visitées périodiquement afin d'observer les différentes étapes de production d'igname. Enfin, la liste de contrôle de Bisset et les matrices d'impacts de Léopold ont permis de faire ressortir les incidences des systèmes culturaux sur les composantes environnementales. il ressort que i) l'igname ne se cultive pas de façon successive sur une même parcelle ; ii) son rendement est élevé lorsqu'elle est produite sur les espaces boisés, les terres neuves et fertiles. Ainsi, elle se place toujours en tête de rotation. iii) l'igname a contribué à la régression de la végétation naturelle de la commune de Ouaké par suite de l'augmentation des zones d'emprise agricole. Face à cette situation, des mesures de sauvegarde sont à apporter pour corriger ce désastre sur la diversité biologique et pour une exploitation durable des ressources naturelles.

() 2013 International Formulae Group. All rights reserved.

Mots clés: Ouaké ressources environnementales, agroforesterie, restauration des sols, pratiques culturales.

\section{INTRODCTION}

Il est connu que plusieurs aspects de la chaîne de valeur de l'igname ont été déjà abordés par des travaux antérieurs, notamment la description du fonctionnement du système de commercialisation et marchandisation des semences de l'igname (Baco et al., 2013) les principaux facteurs de production de fertilisation (Dumont et al., 2010 ; Saïdou et al., 2007), la distribution géographique de la production et les variétés et diversité de l'igname (Baco et al., 2004; Bako et al., 2008 ; Soro et al., 2010). Toutefois, des précisions méritent d'être apportées en ce qui concerne les effets environnementaux au-delà des aspects techniques de la production soulevés par la plupart les auteurs ci-dessus cités.

Au Bénin, la commune de Ouaké fait partie de l'ensemble des communes des trois premiers départements (Borgou, Donga et Collines) producteurs d'igname au plan national (Baco et al., 2013). En effet, la commune de Ouaké, située dans le département de la Donga, produit environ 60000 tonnes d'igname ce qui la place en deuxième position après la commune de Djougou et la place en tête avec $78 \%$ contre $19 \%$ pour le manioc et $3 \%$ pour la patate douce selon les statistiques officielles (Centre Régional de Production Agricole de l'Atacora-Donga CeRPA, 2011). La culture de l'igname est considérée comme une culture 
fournissant l'aliment de base à la population. De ce fait, sa production occupe de plus grandes emblavures (5 000 hectares) selon le CeRPA Op Cite. Selon Baco et al. (2004), la culture de l'igname ne se pratique pas de façon consécutive sur une même parcelle. Et donc, le système de rotation des cultures est recommandé pour garder et améliorer la fertilité des sols.

Mais au-delà de cette exigence qui fait de l'igname une culture consommatrice d'espace, et partant contribuant à la destruction de l'environnement, la Dioscorea est produite soit en monoculture pure, soit dans le cadre d'associations polyculturales. Les zones forestières et savanes qui sont préférentiellement affectées à cette culture se font rares voire inexistantes (ABE, 2001).

Pour la préparation du sol devant servir à la production de l'igname, la majeure partie prend en compte les forêts primaires ou secondaires; au pis-aller, d'un taillis de quelques années. Mais en raison des conséquences de sédentarisation, de la démographie, de l'augmentation des actifs agricoles et de l'accroissement de la demande alimentaire qui concourent à raccourcir à la rotation, les installations se font de plus en plus sur les jachères arborées suffrutescentes ou même sur les jachères herbacées (Dégras, 1986). La production de l'igname n'est donc pas sans effets néfastes sur l'environnement: elle dégrade le couvert végétal car lors du défrichage, les ligneux sont abattus dans les taillis laissant les souches ainsi que les arbrisseaux ou de petits troncs rabattus et émondés que le feu réduira à néant (Dégras, 1986).

Selon l'ABE (ABE, 2001), il ressort qu'à Ouaké, l'extension des surfaces de cultures notamment de l'igname et du coton n'a fait qu'augmenter à long terme les surfaces érodables, les techniques culturales n'étant pas appropriées à la région.

Associée à ce phénomène, la pression démographique sans cesse croissante avec les besoins alimentaires qu'elle engendre, la dégradation des ressources environnementales devient évidente et importante au regard de la progression des espaces dénudés.
Ibrahim (2006), à travers une étude sur le phénomène de dégradation des ressources naturelles, a relevé que la Commune de Ouaké est l'une des zones les plus dégradées au Bénin ; tout comme le Plan d'Action National pour la Lutte Contre la Désertification (Gaou, 2006).

Face à cette situation, il faut trouver une alternative qui prenne en compte la croissance démographique, la gestion des sols et les pratiques agricoles en vue du maintien de la production et d'une gestion durable des ressources naturelles.

Le choix de la localité et du sujet se justifient en amont par la gravité du problème de dégradation des ressources environnementales qui pourrait aboutir à la désertification si les mesures draconiennes et efficaces ne sont pas prises à temps. En aval, les ressources pédologiques et forestières constituent des richesses indispensables et des éléments de sauvegarde de l'environnement. Cette étude vise à :

- Montrer l'importance de l'igname dans la Commune de Ouaké;

- Etudier les impacts environnementaux de la production de l'igname dans la commune de Ouaké.

\section{MATERIEL ET METHODES \\ Zone d'étude}

Ouaké est l'une des quatre (4) communes du département de la Donga. Elle est située au nord-ouest entre les parallèles $9^{\circ}$ $24^{\prime}$ et $9^{\circ} 50^{\prime}$ de latitude nord et les méridiens $1^{\circ} 20^{\prime}$ et $1^{\circ} 35^{\prime}$ de longitude est.

Couvrant une superficie de $624 \mathrm{~km}^{2}$ (ABE, 2001), la commune de Ouaké est limitée au nord par la commune de Copargo, au sud par la commune de Bassila, à l'est par la commune de Djougou et à l'ouest par la République du Togo (Figure 1).

\section{Données et Méthodes \\ Données collectées}

Les données collectées sont l'importance de l'igname pour les populations à travers le nombre de producteurs qui s'y intéresse, la production moyenne annuelle d'igname de la commune; les techniques de 
production, la durée de la jachère, les revenus bruts annuels de la vente d'un hectare d'igname, les espèces préservées sur les parcelles ainsi que leur nombre.

\section{Méthodes de collecte des données}

Les données ont été collectées en deux (2) phases: la phase de pré-enquête et celle d'enquête approfondie.

Pendant la première phase, des entretiens ont eu lieu avec le Responsable Communal pour la Production Agricole (RCPA) et douze (12) Conseillers en Production Végétale (CPA). Cette phase a permis de sélectionner d'abord 16 villages (36\%) meilleurs producteurs d'igname (Figure 2) sur l'ensemble des 44 que compte la commune.

Pendant la deuxième phase, les discussions de groupe ont été organisées avec un groupe de 10 producteurs d'igname dans chacun des 16 villages choisis. Ces discussions ont permis de déterminer d'abord l'importance de l'igname pour les populations, ensuite de recenser les contraintes liées à la production de l'igname et enfin de sélectionner les individus dont leurs exploitations ont été visitées.

\section{Critères de sélection des agriculteurs}

Le choix des agriculteurs a été fait de façon raisonnée:

- avoir au moins cinq années d'expérience dans la production d'igname;

- disposer d'au moins d'un hectare de champ d'igname.

Sur cette base, dix (10) agriculteurs ont été choisis dans chacun des 16 villages retenus lors de la phase de pré-enquête. Ceux-ci ont été soumis aux entretiens individuels.

$\mathrm{Au}$ total, 173 individus ont été enquêtés (Tableau 1) y compris les conseillers du monde agricole.

\section{Collecte des données relatives aux systèmes culturaux}

Une exploitation a été visitée par village soit 16 au total afin d'apprécier la diversité des systèmes culturaux. Ces visites ont permis de prendre part à certains travaux comme le défrichage, le buttage, l'entretien des champs et la récolte des tubercules. Les espèces végétales ligneuses préservées dans les champs d'igname ont été recensées.

\section{Traitement des données \\ Données socio-économiques}

Le revenu moyen brut du producteur de l'igname a été obtenu lors des entretiens avec les producteurs, lequel revenu a permis d'estimer les marges bruts des producteurs par hectare et an.

\section{Méthode d'appréciation des systèmes de culture \\ Le coefficient de Ruthemberg noté $\mathrm{R}$} (Tenté et Sinsin, 2002) a été calculé pour caractériser le système de culture. Il est calculé comme suit :

\section{$R=\frac{\mathrm{Ncx} 100}{\mathrm{Tu}+\mathrm{T} j}$}

Nc: nombre d'années de culture ;

Tu : durée d'utilisation de la terre;

$\mathrm{Tj}$ : durée de la jachère.

Si R > 66\%, il s'agit d'un système de culture permanente ;

Si $\mathrm{R}<33 \%$, il s'agit d'un système de culture itinérante ;

Si $33<\mathrm{R}<66 \%$, il s'agit d'un système de jachère.

\section{Données cartographiques}

A l'aide du Logiciel Arc view 3.2, les coordonnées des meilleurs villages producteurs d'igname ont été projetées sur un fond de carte du milieu d'étude, ce qui a permis de réaliser la Figure 2 montrant la répartition des sites de production d'igname dans la Commune de Ouaké. Les cartes d'occupation du sol de 1975, 1996 et 2006 ont été réalisées et ont permis d'étudier la dynamique des unités d'occupation du sol.

Soit :

- S (1975), la superficie d'une unité d'occupation du sol en 1975;

- S (1996), la superficie d'une unité d'occupation du sol en 1996 ;

- $\triangle \mathrm{S}$, la variation de la superficie de ladite unité entre 1975 et 1996 , telle que

$\triangle \mathrm{S}=\mathrm{S}(1996)-\mathrm{S}(1975)$

- si $\triangle S=0$, il y a stabilité d'occupation du sol; 
- si $\triangle S>0$, il y a progression d'occupation du sol ;

Si $\triangle S<0$, il y a régression d'occupation du sol.

Méthode spécifique à l'analyse des impacts

La liste de contrôle de Bisset et les matrices d'impacts (Léopold et al., 1971) ont permis de faire ressortir les incidences des systèmes culturaux sur les composantes environnementales (Tableau 2).

L'intersection entre les sources d'impacts et les composantes du milieu détermine la nature de l'impact qui sera désignée par les signes plus (+) et moins (-) indiquant respectivement les impacts positifs et ceux négatifs.

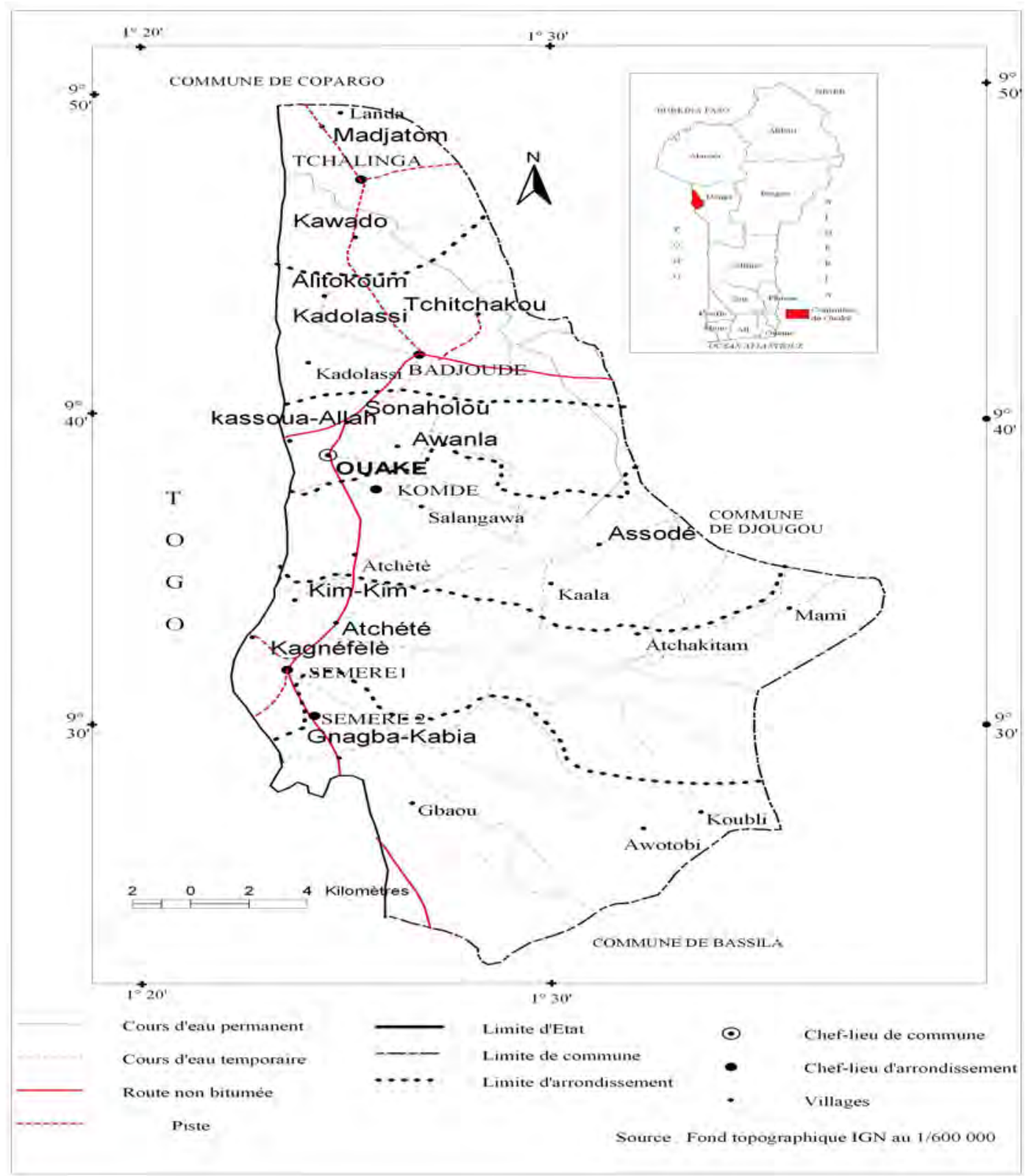

Figure 1: Situation de la commune de Ouaké. 


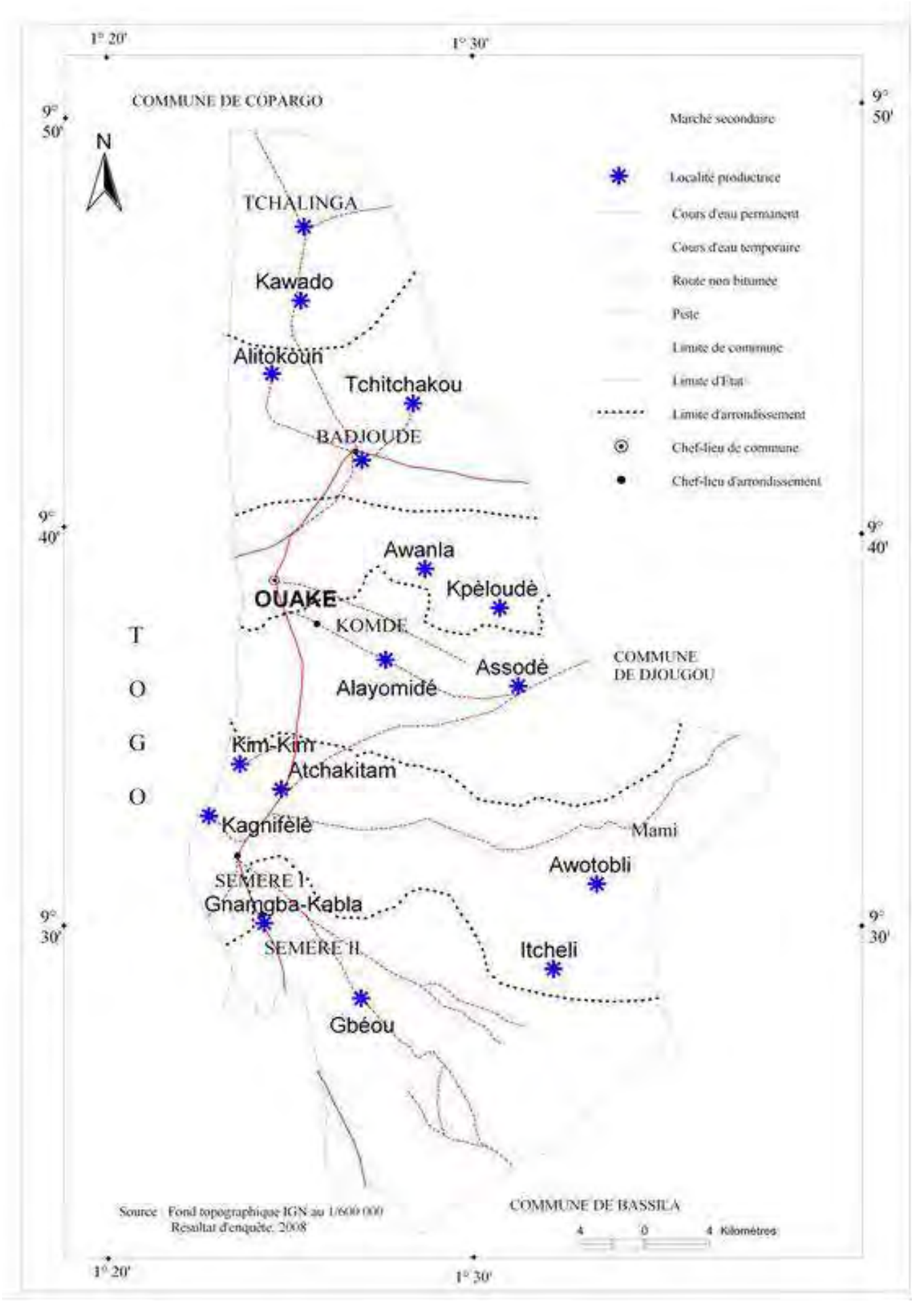

Figure 2: Répartition des sites de production d'igname dans la commune de Ouaké. 
Tableau 1: Effectif des personnes échantillonnées par catégorie.

\begin{tabular}{lllll}
\hline Acteurs & Agriculteurs & RCPA & CPV & Total \\
\hline Effectif & 160 & 12 & 1 & 173 \\
\hline Source: Travaux de terrain, 2011. & & &
\end{tabular}

Tableau 2: Matrice d'identification des composantes et des sources d'impacts

\begin{tabular}{llllllll}
\hline \multicolumn{8}{c}{ Composantes du milieu pouvant être affectées } \\
\hline Sources & $\mathrm{C} 1$ & $\mathrm{C} 2$ & $\mathrm{C} 3$ & $\mathrm{C} 4$ & $\mathrm{C} 5$ & $\mathrm{C} 6$ & $\mathrm{C} 7$ \\
\hline $\mathrm{A}$ & & & & & & \\
\hline $\mathrm{B}$ & \\
\hline Source : Adapté de Léopold et al., 1971.
\end{tabular}

\section{RESULTATS}

\section{Importance de l'igname en termes de production}

L'agriculture demeure la principale activité des populations de la Commune de Ouaké. Les spéculations les plus produites sont l'igname (Discorea spp.), le sorgho (Sorghum spp.), le coton (Gossypium spp.), l'arachide (Arachishy pogea), le maïs (Zea mays) (Figure 3).

La Figure 3 montre que la production d'igname est toujours supérieure à celle des autres cultures pratiquées dans la commune. Cette supériorité se justifie en partie par l'engouement qu'accordent les agriculteurs à cette spéculation. En effet, l'igname représente une plante alimentaire marquant l'identité des populations. Chaque année, sa consommation est subordonnée à des cérémonies entretenant la cohésion des groupes sociaux et activant leur identité : la fête de l'igname. Cette fête de la nouvelle igname dénommée «Kupiu», est accompagnée de la lutte traditionnelle et a souvent lieu au cours du mois d'août. Ces fêtes constituent des occasions de retrouvaille, d'intégration et de réconciliation entre les populations. L'igname contribue à la satisfaction des besoins alimentaires des populations de la commune de Ouaké. Aux dires de l'ensemble des enquêtés, la conservation de l'igname est moins contraignante que celle des céréales. Sur le plan nutritionnel, les enquêtés estiment que l'igname leur fournit de l'énergie permettant d'effectuer les travaux agricoles surtout les plus durs tels que le défrichement et le labour. Enfin, l'igname n'est plus destinée à la seule autoconsommation des populations mais s'insère aujourd'hui dans l'économie marchande.

Le prix de la tonne varie suivant les variétés d'igname et la période de vente. Parfois, il est de 100.000 F CFA (pendant les mois d'abondance aout septembre); 210.000 et $230.000 \mathrm{~F}$ CFA (à partir de décembre jusqu'à la nouvelle récolte). Le revenu moyen brut issu de la vente de l'igname des agriculteurs enquêtés est estimé $425.000 \mathrm{~F}$ $\mathrm{CFA} / \mathrm{ha}$. Ce revenu varie entre 30 et $35 \%$ du revenu agricole par an/ha selon les discussions avec les agents d'encadrement.

\section{Analyse des conséquences de la production de l'igname sur l'environnement}

Les opérations culturales de l'igname sont à la base de la perte des ligneux, l'ameublissement du sol et la perte des terres par érosion. Aussi nombreuses et chronologiques, ces opérations partent du choix de terrain, pour s'achever à la récolte des tubercules. En effet, les producteurs 
choisissent les terres fertiles riches en espèces ligneuses. Ces dernières sont coupées ou calcinées afin de permettre un meilleur ensoleillement de la parcelle. Parfois le défrichage se fait par le feu tardif. Une fois le terrain préparé, le paysan confectionne les buttes. Il consiste à un rassemblement successif de la terre sous la forme d'un cône ou d'une pyramide. Les caractéristiques de la butte dépendent de la nature du sol et surtout de la variété de l'igname à planter. Généralement les buttes destinées aux ignames précoces (Dioscorea cayenensis) sont plus volumineuses que celles réservées aux tardives (Dioscorea rotundata). La taille des buttes varie entre $0,40 \mathrm{~m}$ et $1,10 \mathrm{~m}$ de hauteur et 2,20 à $3,70 \mathrm{~m}$ de diamètre. De ce fait sur un hectare, on peut recenser entre 120 lignes à 30 buttes et 180 lignes à 45 buttes, soit au total entre 3600 et 8100 buttes. C'est l'une des opérations qui grèvent le plus les coûts de production de l'igname, tant elle exige une importante mobilisation de main d'œuvre. (Photos 1 et 2 ).

Le buttage est suivi par la plantation, qui exige un professionnalisme de la part du planteur car la réussite de cette opération dépend de la bonne germination et de la productivité de l'igname. Après la plantation suit le tuteurage qui consiste à couper des arbustes ou la branche des arbres à les introduire dans les buttes afin de permettre à la tige de grimper.

Enfin, la dernière opération qu'est la récolte est pratiquée selon les variétés d'igname : la $1^{\text {ère }}$ récolte pour les ignames précoces, est faite de façon minutieuse à l'aide du coupe-coupe ou d'un piquet préparé pour la circonstance (Photo 3). Elle consiste à creuser la butte, sectionner la partie supérieure de l'igname et la conserver dans la butte, enlever avec soins et précautions le tubercule de la butte de façon à ne pas détruire les racines de la plante. La butte est aussitôt refermée et la partie supérieure conservée continue son développement pour produire les semenceaux.
Cette récolte qui s'effectue généralement entre août et septembre caractérise une période de soulagement pour la plupart des agriculteurs. Les tubercules récoltés permettent de conjurer le moment de soudure et de bien préparer la rentrée scolaire des enfants grâce à la vente de la première récolte.

La $2^{\text {ème }}$ récolte concerne les ignames tardives et les semenceaux des ignames précoces. Elle se fait à la houe et consiste à enlever la totalité des ignames en détruisant la butte dans l'optique de préparer le terrain pour la prochaine culture. Cette récolte s'étend de décembre à mai. Ce moment correspond à la grande période de la commercialisation du produit.

Impacts de la production de l'igname sur les composantes environnementales

Les opérations culturales de l'igname ont des impacts sur les composantes de l'environnement et particulièrement sur les ligneux. Selon les enquêtes de terrain, en moyenne 15 pieds d'arbre sont préservés à l'hectare. Ces espèces sont constituées de: Vitellaria paradoxa, Parkia biglobosa et Daniellia oliveri épargnées pour leur importance commerciale et médicinale.

Par ailleurs, le croisement des sources d'impact avec les composantes du milieu a permis de faire ressortir les composantes du milieu affectées par la production d'igname (Tableau 3).

Le Tableau 3 montre que toutes les activités liées à la production de l'igname ont des impacts positifs sur l'économie locale. En effet, ces activités permettent aux manœuvres locaux de tirer des revenus substantiels. Par exemple, le défrichement d'un hectare coûte en moyenne $25000 \mathrm{~F}$ CFA. Les feux de végétation utilisés pour défricher les parcelles dégagent le $\mathrm{CO}_{2}$ qui pollue l'air; exposent le sol à l'érosion, détruisent les microorganismes et la flore. Mal contrôlés, ces feux incendient parfois les récoltes et les anacarderaies. L'économie locale est ainsi négativement affectée. Le défrichement des 
forêts, le buttage, l'utilisation des tuteurs dénudent le sol et l'exposent à l'érosion.

En définitive, les techniques de production de l'igname ont entraîné la fragmentation des écosystèmes forestiers et la réduction de la durée de jachère (2 à 3 ans). Le coefficient de Rutemberg $\mathrm{R}$ calculé est $70 \%$, valeur supérieure à $66 \%$. Les terres sont exploitées de façon permanente. L'exploitation agricole, la carbonisation et l'exploitation forestière, etc. ont imprimé une dynamique aux unités d'occupation du sol.

\section{Dynamique de l'occupation du sol}

Le paysage de la Commune de Ouaké était majoritairement couvert de végétation vers les années 70 (Figure 4).

Le traitement de l'image LANDSAT TM réalisée en 1975 a permis d'isoler les différents types d'unité d'occupation du sol de l'année 1975.

Les statistiques issues de la carte d'occupation du sol de 1975 sont traduites en Figure 5. Ces statistiques rendent compte de l'évolution des unités d'occupation du sol.

Les images de 1975 montrent la prédominance des savanes arborées et arbustives qui couvrent plus de $50 \%$ de la superficie de la zone d'étude. Les forêts denses et les forêts galeries couvrent environ 4\%. La mosaïque de cultures et jachères est estimée à $0,98 \%$. Les agglomérations n'occupent que $0,1 \%$ du territoire de la commune.

En 1995, les savanes arborées et arbustives ont été majoritairement dégradées et reconverties en savane à emprise agricole (Figure 6).

Cette situation est due aux activités agricoles notamment la culture de l'igname qui se place en tête de la rotation des cultures. Les superficies de certaines unités ont régressé tandis que d'autres en ont augmenté. Les forêts denses et les forêts claires apparaissent sous forme de tâches bien circonscrites. Les mosaïques de cultures et jachères apparaissent sous forme de nombreuses tâches qui s'étendent du nord vers le sud. Les forêts galeries sont moins perceptibles. Elles ne sont apparues qu'au sud de la commune vers Gnangba-Kabia et Awotobi-Mami. Les savanes à emprise agricole gagnent progressivement l'étendue du territoire de la commune.

L'étude de la dynamique d'occupation du sol de 1975 à 1996 a permis d'évaluer la tendance des unités d'occupation du sol (Tableau 4).

Le Tableau 4 montre qu'entre 1975 et 1996, la plupart des unités d'occupation du sol de la zone d'étude ont connu une régression en termes de nombre d'hectares. Les forêts claires et savanes boisées et les savanes arborées et arbustives ont perdu respectivement 17288 ha et 16734 ha soit dans une proportion de $23,36 \%$ et $22,58 \%$. Leur taux de régression respectif est de $1,11 \%$ et $1,07 \%$ par an. En revanche, les superficies de mosaïque de cultures et jachères et des savanes à emprise agricole ont progressé respectivement de 6349 ha et 28988 ha soit dans une proportion de $8,58 \%$ et $39,14 \%$. Leur taux de progression respectif est de $0,40 \%$ et $1,86 \%$ par an. Les forêts galeries ont diminué de $2,33 \%$ et les forêts denses de $0,16 \%$.

En 2006, le paysage de la Commune de Ouaké est dominé par la mosaïque de cultures et jachères (Figure 7). La dynamique d'occupation du sol de 1996 à 2006 a permis d'évaluer la tendance des unités d'occupation du sol (Tableau 5).

Le Tableau 5 révèle en dix ans (1996 à 2006), une large conversion des savanes à emprise agricole, des savanes arborées arbustives et les forêts claires/savanes boisées en mosaïques de cultures et jachères. Les savanes à emprise agricole et les savanes arborées et arbustives ont perdu respectivement 25670 ha et 13459 ha soit dans une proportion de $34,65 \%$ et $18,18 \%$. Leur taux de régression respectif est de 3,5\% et $1,8 \%$ par an. Les forêts claires et savanes boisées, et les forêts galeries ont perdu aussi 3 068 ha et 844 ha soit $4,14 \%$ et $1,14 \%$. Seules les forêts denses sont restées apparemment stables. Pendant ce temps, les superficies des 
mosaïques de cultures et jachères ont augmenté à un rythme soutenu de $67,44 \%$.

Synthèse de l'évolution des unités d'occupation du sol de 1975, 1996 et 2006

Les tendances d'évolution des unités d'occupation du sol de 1975, 1996 et 2006, 1 ont été réalisées (Figure 8).

La Figure 8 montre que de 1996 à 2006, les sept (7) unités d'occupation du sol ont connu différentes tendances. Les savanes arborées-arbustives, les forêts claires, les savanes boisées, les forêts denses et les forêts galeries ont presque disparu. Ces formations n'existent qu'en de très petites proportions et ne dépassent guère $11,91 \%$. En effet, les agglomérations ont fortement évolué de 1975 à 1996 et faiblement de 1996 à 2006. Les mosaïques de cultures et jachères constituent la composante la plus importante $(67,44 \%)$ parmi les unités d'occupation du sol.

En dehors de la régression et de la progression (Tableau 5), il faut aussi noter la stabilité des autres unités. Bien que cette stabilité n'ait pas été totale, il convient cependant de la nuancer. Elle s'est faite constatée au niveau des galeries forestières qui ont été dans l'ensemble épargnées par la pression humaine car d'une proportion de $1,53 \%$ en 1975 , elle n'a régressé qu'à $1,35 \%$ soit un écart de $0,18 \%$.

En somme, la culture de l'igname de par les techniques culturales qui lui sont propres et ses exigences (confection des buttes, terres en friches, caractère héliophile, etc.) contribue significativement à la dégradation de l'environnement, notamment d'ordre végétal et pédologique.

\section{DISCUSSION}

Les coûts de production de l'igname

Comme pour la plupart des produits agricoles cultivés au Bénin, il existe très peu de travaux sur les coûts de production et le degré de profitabilité de la culture d'igname. Cependant, des travaux de Baco et al. (2013) et Adanguidi (2001), il se dégage un constat qui est tout de même réconfortant. En effet, tous les travaux concluent unanimement à la rentabilité de l'igname comparée aux autres cultures (même si certains exagèrent les marges).

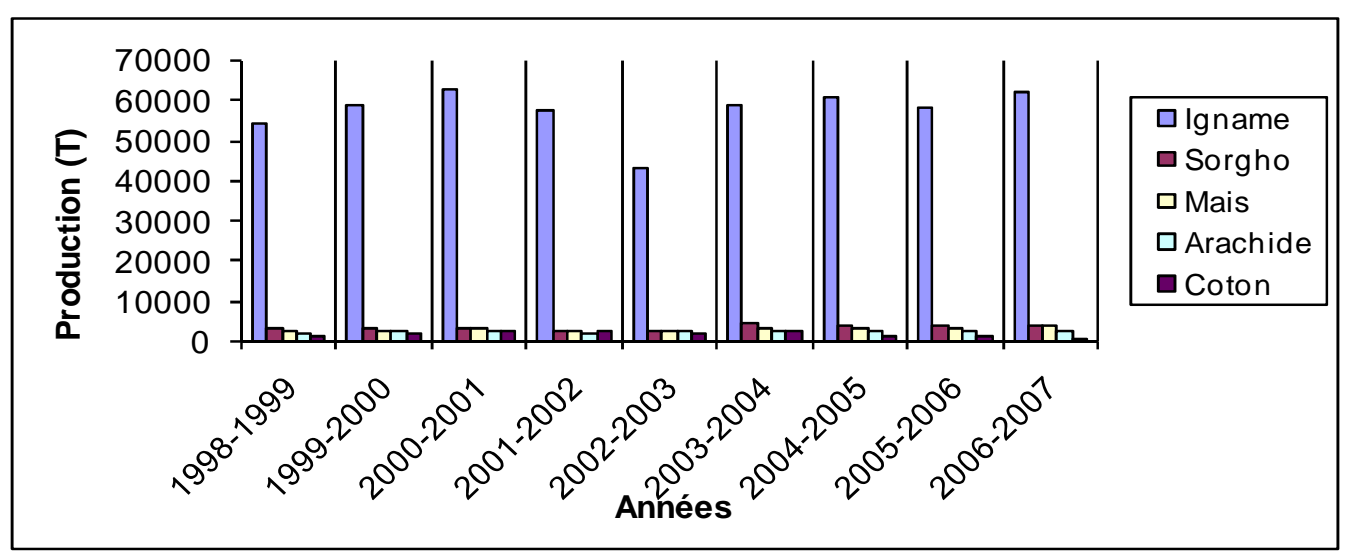

Source: Centre Communal de Production Agricole (CeCPA/Ouaké) et Centre Régional de Production Agricole (CeRPAAtacora-Donga), année 2011.

Figure 3: Evolution de la production des principales spéculations de 1998 à 2007. 
M. GIBIGAYE / Int. J. Biol. Chem. Sci. 7(3): 961-977, 2013

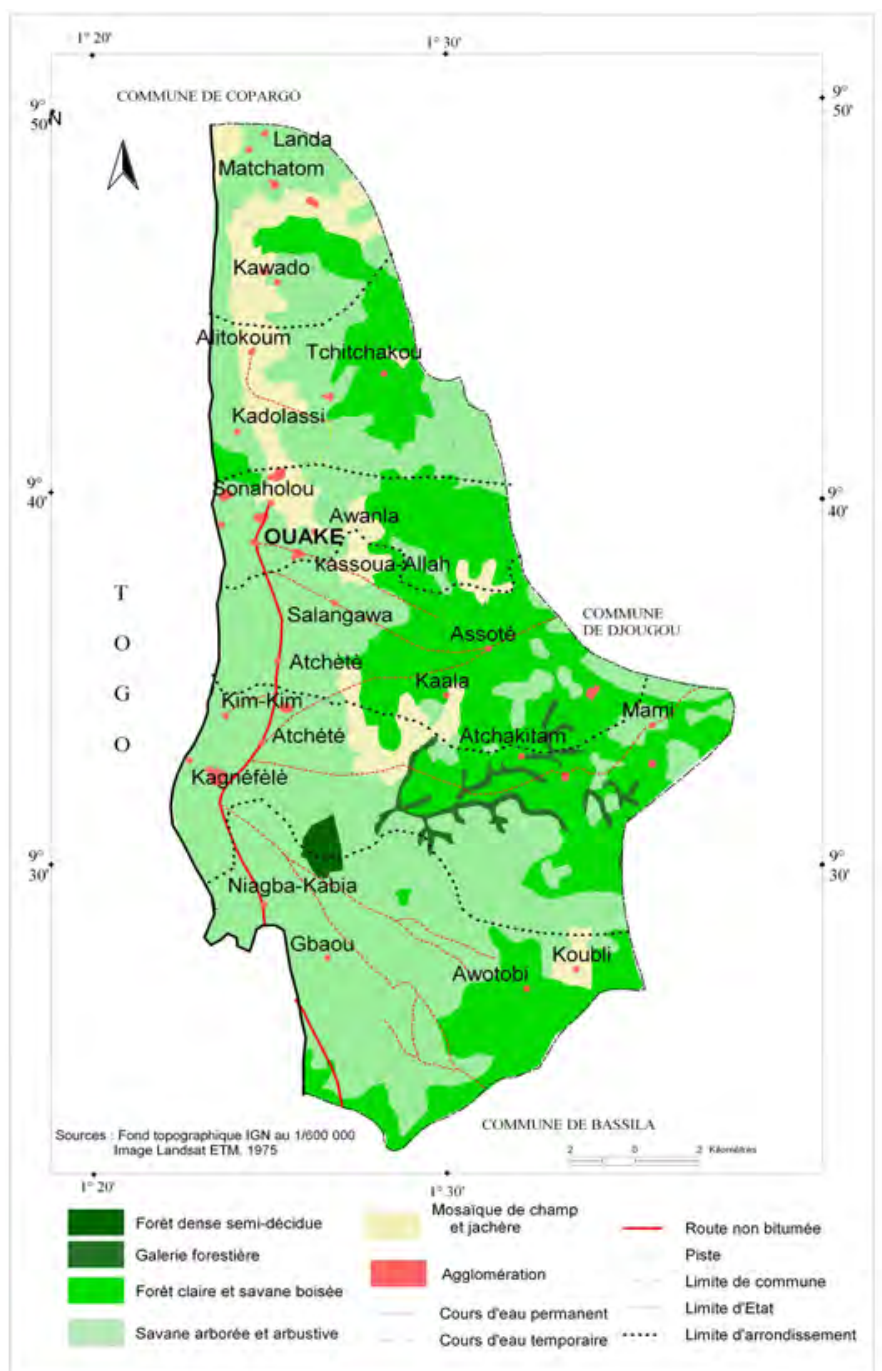

Figure 4: Etat des unités d'occupation du sol en 1975.

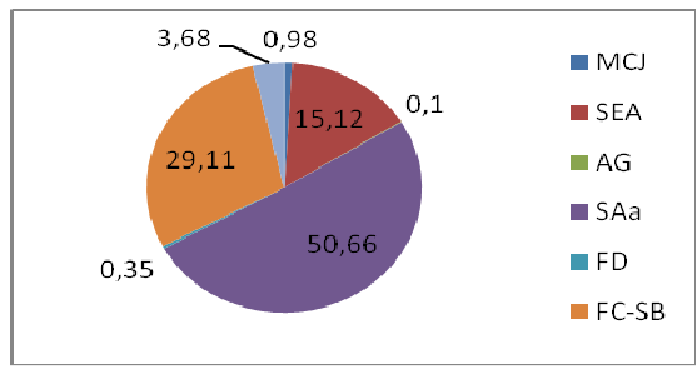

$\mathrm{AG}=$ Agglomération $\mathrm{MCJ}=$ Mosaïque de cultures et jachères ;

SEA = Savane à emprise agricole ; $\mathrm{SAa}=$ Savane arborée- arbustive ;

FC-SB $=$ Forêt claire- Savane boisée $; \mathrm{FD}=$ Forêt dense $; \mathrm{FG}=$ Forêt galerie .

Figure 5 : Etat des unités d'occupation du sol en 1975. 
M. GIBIGAYE / Int. J. Biol. Chem. Sci. 7(3): 961-977, 2013

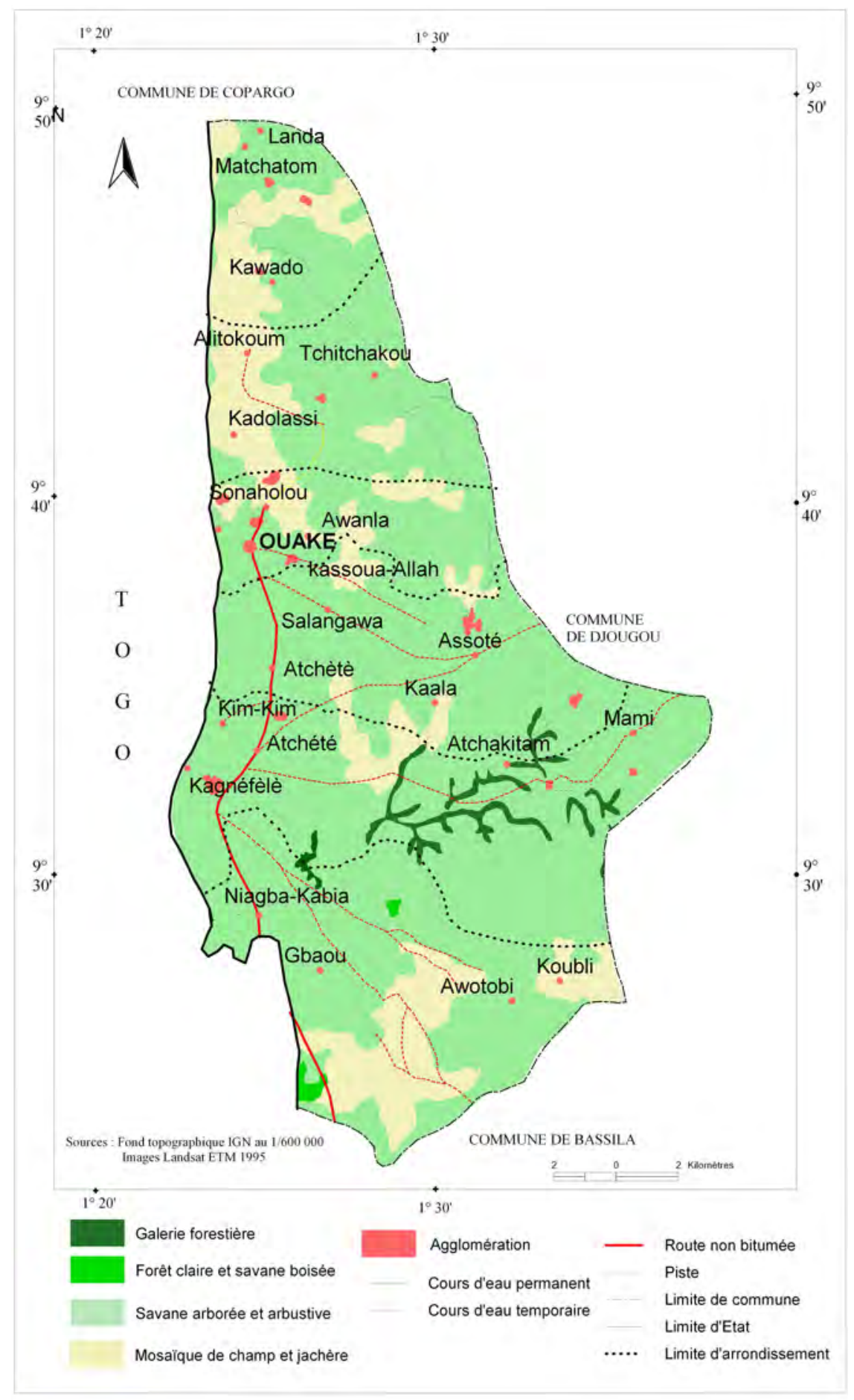

Figure 6 : Carte d'occupation du sol en 1995. 


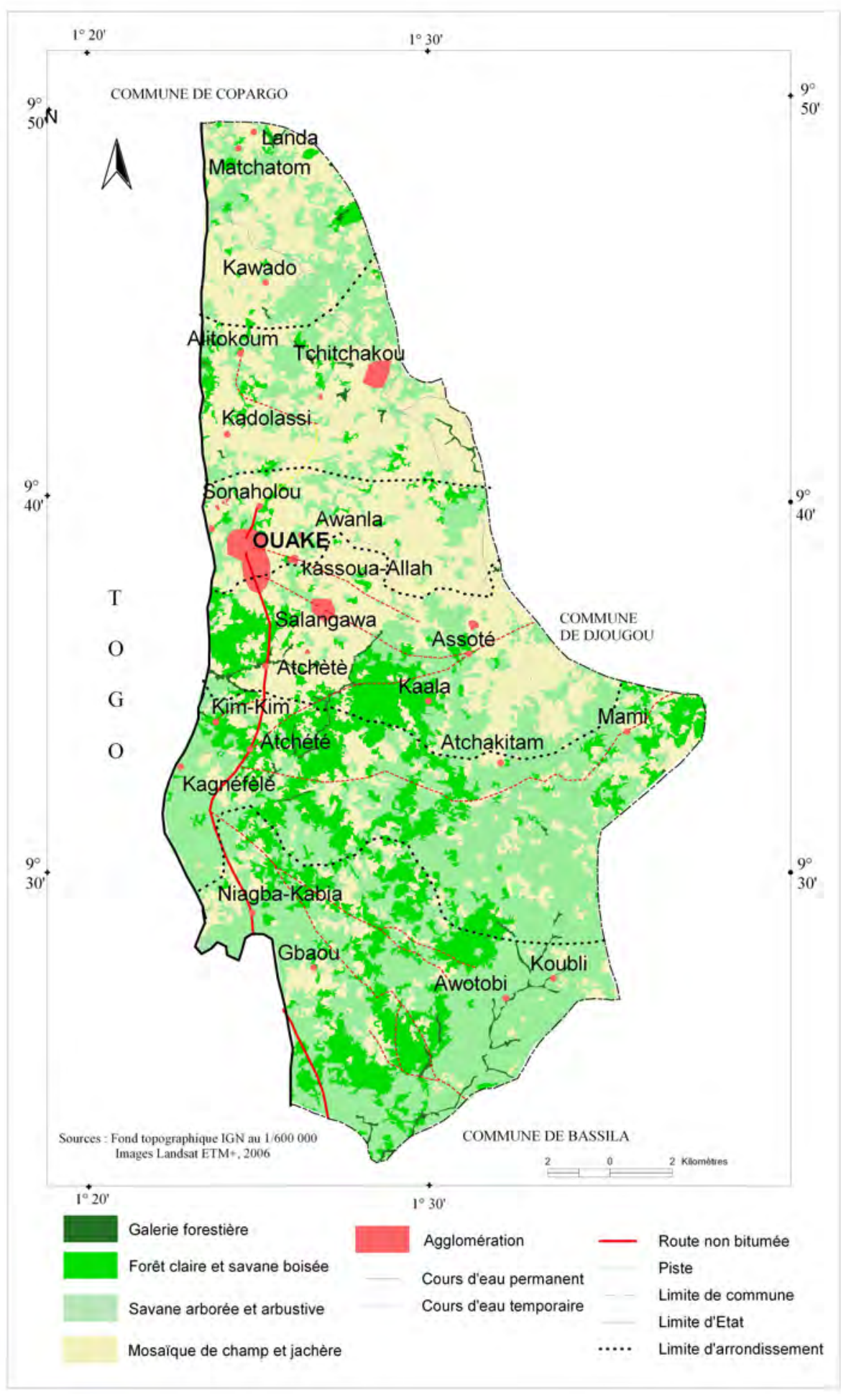

Figure 7 : Occupation du sol en 2005. 


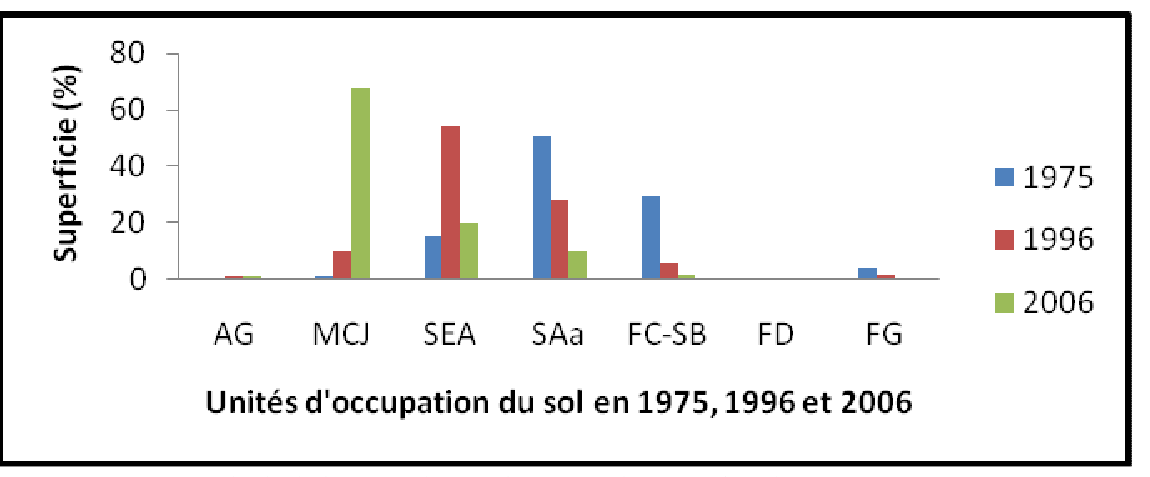

Source : Calculs de l'auteur d'après les cartes d'occupation de 1975, 1996 et 2005.

Figure 8 : Evolution des unités d'occupation du sol de 1975, 1996 et 2006.

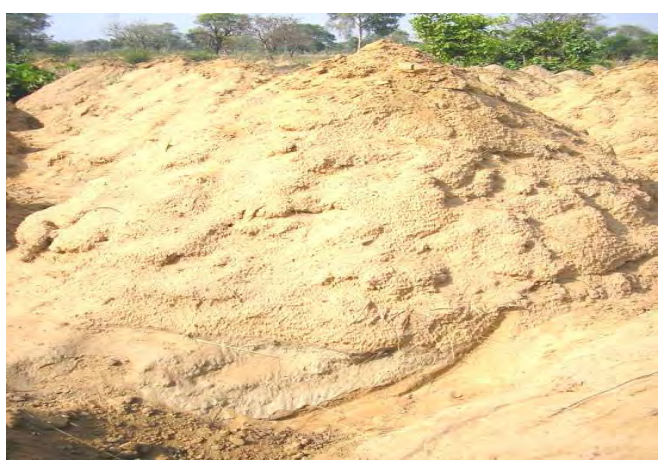

Photo 1: Grosses buttes de la variété d'igname précoce à Agbofou.

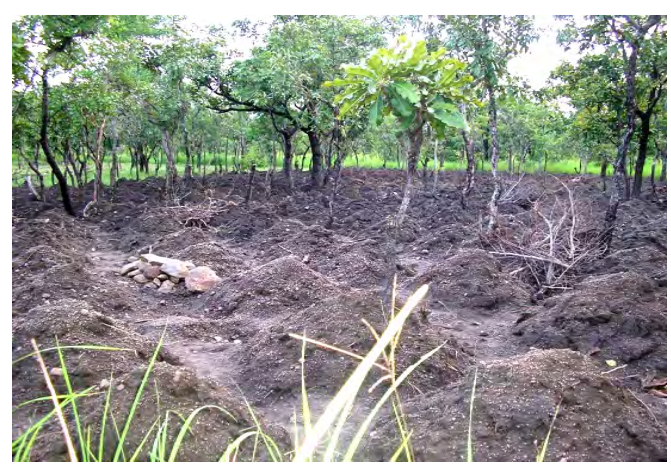

Photo 2: Petites buttes de la variété d'igname tardive à Gbaou.

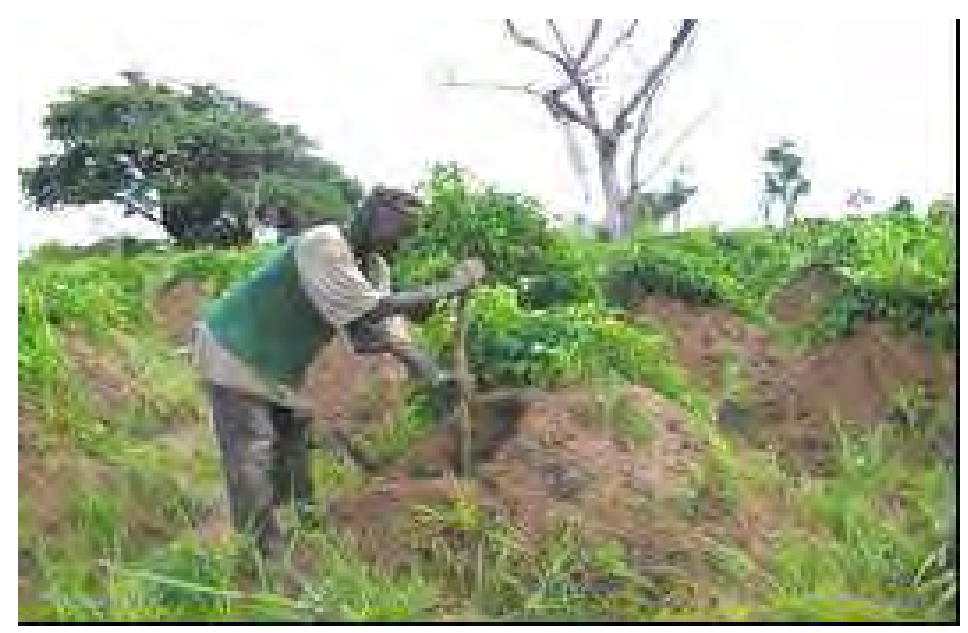

Photo 3 : Un agriculteur en train de récolter l'igname précoce à Gbéta. 
Tableau 3: Matrice de détermination des sources d'impacts et des composantes du milieu touchées par les activités.

\begin{tabular}{|c|c|c|c|c|c|c|c|}
\hline \multirow[b]{2}{*}{$\begin{array}{l}\text { Activités (sources } \\
\text { d'impact) }\end{array}$} & \multicolumn{7}{|c|}{ Composantes environnementales } \\
\hline & Air & Eau (fleuve) & Sol & Flore & Faune & Santé & Economielocale \\
\hline $\begin{array}{l}\text { Défrichement des } \\
\text { forêts par la houe ou } \\
\text { le feu }\end{array}$ & - & - & - & - & - & - & -+ \\
\hline $\begin{array}{l}\text { Abattage des arbres } \\
\text { par le feu ou le } \\
\text { coupe-coupe }\end{array}$ & - & - & - & - & - & - & + \\
\hline Buttage & - & - & - & - & - & - & + \\
\hline Sarclage & - & - & - & - & - & - & + \\
\hline $\begin{array}{l}\text { Recherche des } \\
\text { tuteurs }\end{array}$ & - & - & - & - & - & - & + \\
\hline Récolte & - & - & - & - & - & - & + \\
\hline
\end{tabular}

Tableau 4 : Evolution des unités d'occupation du sol de 1975 à 1996.

\begin{tabular}{lccccc}
\hline \multirow{2}{*}{$\begin{array}{l}\text { Unités d'occupation du } \\
\text { Sol }\end{array}$} & \multicolumn{2}{c}{ Superficie (\%) } & Variation (ha) & Variation (\%) & Tendances \\
\cline { 2 - 3 } AG & $\mathbf{1 9 7 5}$ & $\mathbf{1 9 9 6}$ & & & \\
MCJ & 0,10 & 0,81 & +524 & $+0,71$ & Progression \\
SEA & 0,98 & 9,56 & +6349 & $+8,58$ & Progression \\
SAa & 15,12 & 54,26 & +28988 & $+39,14$ & Progression \\
FC-SB & 50,66 & 28,08 & -16734 & $-22,58$ & Régression \\
FD & 29,11 & 5,75 & -17288 & $-23,36$ & Régression \\
FG & 0,35 & 0,19 & -118 & $-0,16$ & Régression \\
\hline
\end{tabular}

$+=$ Progression- $=$ Régression $0=$ Stabilité

Source : Calculs de l'auteur d'après les cartes d'occupation de 1975 et 1996.

Tableau 5 : Evolution des unités d'occupation du sol de 1996 à 2005.

\begin{tabular}{|c|c|c|c|c|c|}
\hline \multirow{2}{*}{$\begin{array}{l}\text { Unités d'occupation du } \\
\text { sol }\end{array}$} & \multicolumn{2}{|c|}{ Superficie (\%) } & \multirow{2}{*}{$\begin{array}{c}\text { Variation } \\
\text { (ha) }\end{array}$} & \multirow{2}{*}{$\begin{array}{c}\text { Variation } \\
(\%)\end{array}$} & \multirow[t]{2}{*}{ Tendances } \\
\hline & 1996 & 2006 & & & \\
\hline $\mathrm{AG}$ & 0,81 & 1,04 & 173 & $+0,23$ & Progression \\
\hline MCJ & 9,56 & 67,44 & 42868 & $+57,88$ & Progression \\
\hline SEA & 54,26 & 19,61 & 25670 & $-34,65$ & Régression \\
\hline SAa & 28,08 & 9,9 & 13459 & $-18,18$ & Régression \\
\hline FC-SB & 5,75 & 1,61 & 3068 & $-4,14$ & Régression \\
\hline FD & 0,19 & 0,19 & 0 & 0 & Stabilité \\
\hline FG & 1,35 & 0,21 & 844 & $-1,14$ & Régression \\
\hline
\end{tabular}

Importance de l'igname dans la Commune de Ouaké

L'igname est l'un des tubercules les plus consommés au nord du Bénin. A Ouaké, la valeur d'un homme se mesurait par rapport à la taille de l'exploitation agricole notamment la superficie ensemencée en igname. L'étendue de la plantation d'igname détermine l'importance sociale du paysan. Possédée une grande plantation d'igname confère au propriétaire une certaine renommée étant donné qu'il est difficile de le réaliser. 
Cette spéculation renforce la base culturelle des producteurs en ce sens qu'avant sa consommation, des rituelles sont organisées. Ce constat avait été déjà fait par Baco et al. (2008) et Dumont (2010) qu'ils qualifient sous l'expression civilisation de l'igname, civilisation dans laquelle coutumes et rites sont marqués par son cycle.

L'igname fournit plus d'énergie que les autres vivriers. Cette énergie est nécessaire pour réaliser les travaux de préparation du terrain, de buttage, etc. selon une étude, Baco et al. (2008) ont montré qu'un repas d'igname satisfait $100 \%$ des besoins en énergie et en protéines, $130 \%$ des besoins en calcium et $80 \%$ de besoins en fer d'un homme adulte. Les études effectuées par l'Institut National des Recherches Agricoles du Bénin (INRAB) en 1996 ont révélé que l'igname fournit en moyenne $107 \mathrm{~kg}$ de protéines par hectare contre $37 \mathrm{~kg}$ pour le manioc, $82 \mathrm{~kg}$ pour le maïs et $78 \mathrm{~kg}$ pour le soja. Ces résultats antérieurs justifient l'intérêt qu'accordent les agriculteurs à l'igname compte tenu de sa richesse en protéine. Outre l'importance culturelle, énergétique de l'igname, l'igname représente une source de revenu pour la population, comme le suggère nos résultats cidessus. La pression des marchés due à la forte demande de l'igname dans les villes non productrices est un facteur de la forte production. Selon Soro et al. (2010) et Bricas (2013), l'igname tend à gagner des marchés moins traditionnels comme ceux des villes du Sahel, où il constitue un des aliments privilégiés de la diversification alimentaire. Face à l'importance socio-économique et culturelle de l'igname, sa production prend donc de l'ampleur entraînant des externalités négatives sur l'environnement.

\section{L'igname dans les systèmes nationaux de culture}

L'igname est une culture très exigeante au point de vue des conditions agronomiques. Elle requiert non seulement des terres fertiles, mais aussi des hauteurs de pluie supérieures à $1200 \mathrm{~mm}$, réparties sur 5 à 6 mois et une période d'insolation équivalente. C'est cette exigence qui fait qu'en culture traditionnelle, l'igname se retrouve toujours en tête d'assolement et revient très généralement une seule fois après le maïs et/le sorgho dans la rotation à cause de la baisse du niveau de fertilité des sols. Dans ce cas précis, les tiges de mil sont utilisées comme tuteur de l'igname. Cette quête permanente de terre fertile explique très largement le caractère itinérant de la culture de ce tubercule.

La monoculture de l'igname est traditionnellement multivariétale. Selon Baco et al. (2007). L'éventail du matériel végétal utilisé reste diversifié aussi longtemps que la production se trouve dirigée vers l'autoconsommation. D'après les travaux conduits par Baco et al. (2013) dans quelques villages du Bénin septentrional, «l'agriculture locale exploite quatre espèces d'ignames se distribuant en 42 cultivars différents, mais 8 cultivars de Dioscorea -rotundata couvrent cependant $70 \%$ de la surface cultivée».

Les cas de polyculture, où l'igname partage la surface du champ avec d'autres espèces vivrières, pour la plupart de cycle végétatif annuel sont généralement fréquents (Soro et al., 2010). Cette pratique tout comme celles relatives aux techniques d'association permet de rentabiliser les investissements en main d'œuvre et d'atténuer la pénibilité des travaux préparatoires des champs d'igname.

Cependant, selon les travaux de Baco (2007) ce sont les cas d'association de l'igname à d'autres cultures qui sont courant dans les systèmes de cultures traditionnels. L'igname cohabite ainsi avec les légumineuses, les céréales (mil-sorgho, maïs, et même riz), les melons, les gombos et parfois momentanément avec d'autres tubercules (patate douce) ou racine (manioc).

\section{Conséquences de la production de l'igname sur l'environnement}

La culture de l'igname telle qu'elle est menée actuellement participe à la perte des ligneux. Dans toutes les rotations, l'igname vient en tête de culture occasionnant la perte massive des ligneux. De pareil constat a été fait par Adanguidi (2001). L'ameublissement du sol dû à la fabrication des buttes d'igname entraîne le départ des nutriments, conduisant à l'appauvrissement des terres. Par conséquent, certains agriculteurs migrent vers les espaces 
alors que d'autres vont vers les départements des collines où ils s'installent dans les forêts classées. Les résultats des travaux de Odjoubéré (2011) ont confirmé cette migration. En effet, selon l'auteur, la zone tampon de la forêt classée des Monts Kouffé est en majorité occupée par les colons agricoles venus de la Commune de Ouaké. En dehors de l'agriculture, ils se livrent intensément à la fabrication du charbon, une activité très destructrice du couvert végétal. Dans la Commune de Savè, Biaou et Tchégnon (1995) ont également fait le même constat et ont enfin conclu que la technique de production d'igname n'est pas respectueuse de l'environnement.

\section{Conclusion}

L'étude des effets de la culture de l'igname sur le système agroforestier dans la Commune Ouaké a permis de mettre en évidence les principaux paramètres suivants : les emblavures liées à la culture de l'igname, la place de l'igname dans la commune de Ouaké; les techniques culturales de l'igname ; les effets de la culture sur les ressources environnementales. Cependant, cette étude est loin d'aborder toutes les préoccupations relatives à cette thématique notamment toutes les questions liées à la récolte, au stockage et surtout les contraintes liées à la conservation de l'igname, laquelle ne permet pas d'avoir d'abord une lisibilité sur les formes contractuelles sur le marché des ignames et ensuite sur la profitabilité des transactions.

$\mathrm{Au}$ total, la filière igname est encore porteuse d'espérance comme un des moyens domestiques de résolution des questions de sécurité alimentaire du pays. L'igname dispose en effet d'incontestables atouts qui autorisent à la considérer comme une culture d'avenir pour l'économie nationale.

Les investigations ont révélé qu'en amont, l'igname offre aux populations de la zone d'étude, des avantages tant sur le plan alimentaire que sur la plan socioéconomique; ce qui fait d'elle une culture pratiquée par environ $95 \%$ des paysans.

En aval, la technique culturale de l'igname fait perdre des ressources végétales. Les feux de végétation, surtout ceux tardifs émis lors de la préparation du sol contribuent à la perte de la biodiversité. Ces feux ne laissent aucune chance aux espèces en phase de floraison ou de fructification d'atteindre leur stade de maturation et constituent la cause de la repousse des graminées au détriment des ligneux et la prolifération des espèces végétales hostiles à la restauration du sol. Ils sont aussi responsables de la transformation des forêts en savanes et des savanes en zones dénudées dont la conséquence est la désertification.

La gestion rationnelle de l'environnement s'impose et de façon urgente. Elle devrait passer par l'instauration à tous les niveaux, de bonnes pratiques agricoles respectueuses de l'environnement. L'agriculture de conservation, l'agroforesterie, la restauration / conservation des sols ainsi que les jachères en sont quelques-unes ces bonnes pratiques agricoles. Elles constituent aussi des options d'aménagement facilement réalisable par les producteurs car n'exigent ni investissements financiers importants, ni engins agricoles lourds et les agriculteurs peu formés peuvent s'en approprier. A ce titre, il convient de définir quelques actions dont la mise en œuvre ne doit pas faire l'affaire d'une seule institution encore moins de quelques individus:

- élaborer et mettre en application un plan de sensibilisation et d'information des populations sur l'effet de leurs pratiques culturales sur l'environnement ;

- vulgariser et soutenir les techniques de production de l'igname déjà existantes dans tous les villages du secteur d'étude, comme c'est le cas de l'association du gliricidia (Gliricidia sepium) avec l'igname.

\section{REFERENCES}

ABE (Agence Béninoise pour l'Environnement). 2001. Plan municipal d'actions environnementales de la commune de Ouaké : profil environnemental. Cotonou, 55 p.

Adanguidi J. 2001. Réseaux, Marchés et Courtage : La filière igname au Bénin 1990 à 1997 Thèse de doctorat, Université de Hohenheim, 301 p. 
Baco MN, Moumouni I, Saka AK, Dossou RA, Egah J, Assiedu E. 2013. De la gratuité à la marchandisation des semences d'igname au Bénin : quelles implications sur la sécurité alimentaire. 1st conference of African research on agriculture, Food, and Nutrition, Yamoussoukro, Côte d'Ivoire.

Baco MN, Biaou G, Pham JL, Lescure JP. 2008. Facteurs géographiques et sociaux de la diversité des ignames cultivées au Nord Bénin. Cahiers Agricultures, 17(2): 172-7.

Baco MN, Tostain S, Mongbo RL, Daïnou O, Agbangla C. 2004. Gestion dynamique de la diversité variétale des ignames cultivées (Dioscorea cayenensis-D. rotundata) dans la commune de Sinendé au nord Bénin. Sciences-New York, 139: $18-24$.

Biaou G, Tchégnon P. 1995. Migrations rurales, systèmes d'exploitation agricole et gestion des ressources naturelles : cas de la sous-préfecture de Savè'. In Système national de recherche agricole. Actes des Premières Journées Scientifiques: Agriculture durable, atouts et contraintes, p. 17-18.

Bricas N. 2013. Les marchés alimentaires urbains en Afrique de l'Ouest :facteurs de dépendance ou d'entraînement de l'agriculture ? 1st conference of African research on agriculture, food, and nutrition Yamoussoukro, Côte d'Ivoire.

Centre Régional de la Production Agricole (CeRPA-Atacora-Donga). 2011. Rapport annuel de la campagne agricole, Ouaké, Bénin, 33 p.

Degras L. 1986. L'Igname: Plante à Tubercule Tropicale. Edition GPM Maisonneuve et Larose : Paris ; 408 p.

Dumont R, Zoundjihekpon J, Vernier P. 2010. Origine et diversité des ignames Dioscorea rotundata Poir. Domestication des ignames sauvages en Afrique. Cahiers Agricultures, 19(4): 255-61.

Gaou IM. 2006. Dynamique de la population et problèmes de bois-énergie dans la commune de Ouaké. Mémoire de maîtrise en Géographie, DGAT/ FLASH/ UAC, Abomey-calavi, Bénin, 61p.

Ibrahim D. 2006. Contribution à l'étude socioéconomique et à la gestion des parcs à néré (Parkia biglobosa, (Jacq) R. Br. Ex. G. Don) dans la commune de Ouaké. Mémoire de maîtrise en Géographie, DGAT/FLASH/UAC, Abomey-calavi, Bénin, 85p.

Institut National de la Recherche Agricole au Bénin. 1996. Plan directeur de la recherche agricole du Bénin (Volume II). Deuxième partie : Plan de développement à long terme. Programme sectoriel, Rapport annuel, Cotonou, 157p.

Léopold LB, Clark FE, Hanshaw BB, Balsey JR. 1971. A Procedure for Evaluation Environmental Impact. Geological Survey Circular $\mathrm{N}^{\circ}$ 645, US Geological Survey: Washington D.C., 56p.

Odjoubéré J. 2011. Poussée de la carbonisation à Okouta-ossé, un village périphérique de la forêt classée des Monts Kouffé : problèmes et perspectives pour une gestion durable des ressources végétales. Mémoire de Master II en Géosciences de l'environnement et développement durable, CIFRED, FLASH, Université d'Abomey-Calavi, Bénin, 126p.

Saidou A, Adjei-Nsiah S, Koussou D, SakyiDawson O, Kuyper TW. 2007. Sécurité foncière et gestion de la fertilité des sols : études de cas au Bénin et au Ghana. Cahiers Agricultures, 16(5): 405-412.

Soro D, Dao D., Girardin O. Bi TT, Tschanneu BA, 2010. Adoption d'innovations en agriculture et Cote d'Ivoire: cas de nouvelle variétés d'igname. Cahiers Agricultures, 19(6) 403-410

Tenté B, Sinsin B. 2002. Diversité et structure des formations arborescentes du secteur Perma-Toucountouna dans la chaîne de l'Atacora (Bénin). Vég. Burkina Faso, 6: 31-42. 